\title{
BMJ Open Respiratory symptoms are more Respiratory Research common among short sleepers
independent of obesity
}

Erla Björnsdóttir, ${ }^{1,2}$ Christer Janson, ${ }^{3}$ Eva Lindberg, ${ }^{3}$ Erna Sif Arnardottir, ${ }^{1,4}$ Bryndís Benediktsdóttir, ${ }^{1,4}$ Judith Garcia-Aymerich, ${ }^{5,6,7}$ Anne Elie Carsin,, ${ }^{5,6,7}$ Francisco Gómez Real, ${ }^{8}$ Kjell Torén, ${ }^{9}$ Joachim Heinrich, ${ }^{10,11}$ Dennis Nowak, ${ }^{10}$ José Luis Sánchez-Ramos, ${ }^{12}$ Pascal Demoly, ${ }^{13}$ Sandra Dorado Arenas, ${ }^{14}$ Ramon Coloma Navarro, ${ }^{15}$ Vivi Schlünssen, ${ }^{16,17}$ Chantal Raherison, ${ }^{18}$ Debbie L Jarvis, ${ }^{19,20}$ Thorarinn Gislason ${ }^{1,4}$

To cite: Björnsdóttir E, Janson C, Lindberg E, et al. Respiratory symptoms are more common among short sleepers independent of obesity. BMJ Open Resp Res 2017;4:e000206. doi:10.1136/ bmjresp-2017-000206

Received 18 April 2017 Accepted 27 June 2017

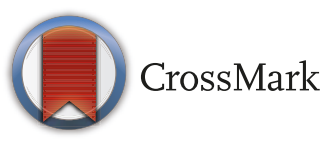

For numbered affiliations see end of article.

Correspondence to Dr Thorarinn Gislason; thorarig@landspitali.is

\section{ABSTRACT}

Introduction Sleep length has been associated with obesity and various adverse health outcomes. The possible association of sleep length and respiratory symptoms has not been previously described. The aim of this study was to investigate the association between sleep length and respiratory symptoms and whether such an association existed independent of obesity.

Methods This is a multicentre, cross-sectional, population-based study performed in 23 centres in 10 different countries. Participants $(n=5079,52.3 \%$ males) were adults in the third follow-up of the European Community Respiratory Health Survey III. The mean \pm SD age was $54.2 \pm 7.1$ (age range 39-67 years). Information was collected on general and respiratory health and sleep characteristics.

Results The mean reported nighttime sleep duration was $6.9 \pm 1.0$ hours. Short sleepers ( $<6$ hours per night) were $\mathrm{n}=387(7.6 \%)$ and long sleepers ( $\geq 9$ hours per night) were $\mathrm{n}=271(4.3 \%)$. Short sleepers were significantly more likely to report all respiratory symptoms (wheezing, waking up with chest tightness, shortness of breath, coughing, phlegm and bronchitis) except asthma after adjusting for age, gender, body mass index (BMI), centre, marital status, exercise and smoking. Excluding BMI from the model covariates did not affect the results. Short sleep was related to 11 out of 16 respiratory and nasal symptoms among subjects with $\mathrm{BMI} \geq 30$ and 9 out of 16 symptoms among subjects with $\mathrm{BMl}<30$. Much fewer symptoms were related to long sleep, both for subjects with BMI $<30$ and $\geq 30$.

Conclusions Our results show that short sleep duration is associated with many common respiratory symptoms, and this relationship is independent of obesity.

\section{INTRODUCTION}

Over the past several decades, the prevalence of obesity has grown to epidemic proportions. ${ }^{12}$ At the same time, there has been a similar epidemic of chronic sleep deprivation. ${ }^{2-4}$ Studies have shown that the average sleep duration has decreased 1-2 hours over the last decades. ${ }^{2}$ According to annual surveys

\section{Key messages}

\section{What is the key question?}

Is sleep length associated with respiratory health and is this relationship independent of obesity?

\section{What is the bottom line?}

Short sleep duration is associated with many common respiratory symptoms, and this relationship is independent of obesity.

\section{Why read on?}

Respiratory symptoms have so far not been the main focus in studies on causal pathways of short sleep duration but, given our results, some respiratory symptoms might directly impact sleep quality and increase the risk of short sleep duration.

done by the National Sleep Foundation, by 1998, only $35 \%$ of American adults were obtaining 8 hours of sleep and that number had fallen to $20 \%$ on weekdays by $2008 .^{2}$ It has also been reported that up to $30 \%$ of adult men and women between the ages of 30 and 64 years sleep less than 6 hours per night. ${ }^{4}$

Sleep duration has been related to many important adverse effects on health. ${ }^{5-10}$ Short sleep duration has been associated with diabetes, hypertension, ${ }^{10}$ cardiovascular disease $(\mathrm{CVD})^{8}{ }^{9}$ and increased mortality. ${ }^{5-7}$ A recent meta-analysis of cross-sectional studies on sleep duration and the metabolic syndrome showed that sleep duration under 5 hours significantly increased the risk for metabolic syndrome independently of other known risk factors. ${ }^{11}$

Obesity is strongly associated with respiratory health, and sleep length is associated with obesity. The adverse health effects of sleep duration have been associated with body weight as both short sleepers and long 
sleepers are at an increased risk for obesity. ${ }^{12-14}$ In a recent meta-analyses of 16 studies including in total 285452 adults, both short sleep duration and long sleep duration were associated with an increased risk of weight gain, but only short sleep duration increased the risk of obesity. ${ }^{15}$ However, obesity has also been identified as a risk factor for both asthma ${ }^{16}$ and chronic bronchitis, ${ }^{17}$ as well as obstructive sleep apnoea (OSA) ${ }^{18}$ In addition, several respiratory symptoms are related to obesity. ${ }^{19} 20$ Despite the reported associations between sleep length and obesity, and obesity and respiratory health, to the best of our knowledge, no published studies have shown whether there is an independent association between sleep duration and respiratory symptoms. Since existing data show associations of both obesity and sleep duration and obesity and respiratory health, it is important to explore the associations of sleep duration and respiratory health and the role of obesity in this context.

The aim of this study was to investigate the possible association between sleep length and respiratory symptoms and whether it is independent of obesity.

\section{METHODS}

\section{Subjects}

This is a cross-sectional study, and participants are adults taking part in the third follow-up of the European Community Respiratory Health Survey (ECRHS, www. ecrhs.org) III, an international, multicentre, population-based study of asthma and allergy, which was first performed in the early 1990s. Detailed descriptions of the methods for ECRHS I and ECRHS II have been published elsewhere. $^{21}{ }^{22}$ Briefly, participating centres were first randomly selected samples of subjects aged 20-44years. Participants completed a short postal questionnaire about asthma and asthma-like symptoms (sample 1). Additionally, about $20 \%$ random subsamples of responders were invited for a more detailed questionnaire administered by an interviewer (sample 2). Participants in this study belong to sample 2 .

Ethical approval for the study from local research ethics committees and written consent from participants were obtained.

\section{Questionnaires and measurements}

Participants completed the core ECRHS questionnaires on smoking, other lifestyle and environmental factors, general and respiratory health and chronic disorders. 'Ever asthma' was defined as reporting ever having had asthma where the diagnosis had been confirmed by a doctor, and 'Current asthma' was defined as having at least one asthma-related symptom in the last 12 months. Participants were also asked whether they had a problem with sneezing or a runny or blocked nose without having the influenza in the last 12 months.

Chronic obstructive pulmonary disease (COPD) was considered present if subjects reported physician-diagnosed COPD. Chronic bronchitis was defined as having cough or phlegm for at least 3 months every year for at least two consecutive years. The presence of CVD was determined by a positive response to ever having angina, heart attack, coronary heart disease or stroke. Nocturnal gastro-oesophageal reflex (nGOR) was defined as reporting heartburn or belching when in bed more often than once a week for the last 3 months.

Information on diagnosed depression, hypertension, diabetes and stroke was also collected.

Subjects were asked how often they usually exercised so much that they get out of breath or sweat. Answers ranged from never to every day, and those who answered $\geq 2$ times per week were considered to exercise on a regular basis.

Height and weight was measured by field workers according to a standardised procedure.

\section{Sleep-related questions}

All participants were asked to fill in a short questionnaire on their sleep (see supplement). Participants answered the question: how much sleep do you estimate that you get on average each night? They were classified as short sleepers ( $<6$ hours/night), normal sleepers (6-9 hours/ night) and long sleepers ( $\geq 9$ hours/night), in accordance with classifications used in most previous studies on health effects of sleep duration. ${ }^{7-9} 1213$ Participants also answered the Epworth Sleepiness Scale. ${ }^{23}$

\section{Statistical methods}

Data are presented as number and percentage or means \pm one $\mathrm{SD}$, depending on distribution. For bivariate analysis, the $\chi^{2}$ test, t-test and one-way analysis of variance were used for nominal and continuous variables. Logistic regression was used for multivariable analyses to estimate the association between sleep length and respiratory symptoms. Given that obesity is strongly related to both sleep length and to respiratory disorders, multivariable models were built both with and without BMI adjustment. We also stratified results according to BMI into two groups: subjects with $\mathrm{BMI}<30$ and $\mathrm{BMI} \geq 30$. The logistic regression models for the association between short sleep and respiratory symptoms and disorders were also fitted separately for each country. Results for the association were pooled across countries using random effects meta-analysis. Heterogeneity between the countries in the association between short sleep and respiratory heath were analysed. STATA V.13.0 was used for all statistical analyses.

\section{RESULTS}

\section{The study cohort}

We included a total of 5079 subjects $(52.3 \%$ males $)$ from 23 centres in 10 countries (Australia, Britain, Denmark, Estonia, France, Germany, Iceland, Norway, Spain and Sweden). 
Table 1 Characteristics of short, normal and long sleepers

\begin{tabular}{|c|c|c|c|c|c|}
\hline & $\begin{array}{l}\text { Short sleepers } \\
\text { ( }<6 \text { hours per } \\
\text { night) } n=387\end{array}$ & $\begin{array}{l}\text { Normal sleepers } \\
\text { (6-9hours per } \\
\text { night) } n=4475\end{array}$ & $\begin{array}{l}\text { Short compared } \\
\text { with normal } \\
\text { sleepers } \\
\text { p Value }\end{array}$ & $\begin{array}{l}\text { Long sleepers } \\
\text { ( } \geq 9 \text { hours per } \\
\text { night) } \mathbf{n = 2 1 7}\end{array}$ & $\begin{array}{l}\text { Long compared } \\
\text { with normal } \\
\text { sleepers } \\
\text { p Value }\end{array}$ \\
\hline Male (\%) & 48.3 & 48.2 & 0.957 & 37.8 & 0.003 \\
\hline Age (years) & $55.1 \pm 6.4$ & $54.1 \pm 7.1$ & 0.009 & $55.8 \pm 7.1$ & $<0.001$ \\
\hline $\mathrm{BMI}\left(\mathrm{kg} / \mathrm{m}^{2}\right)$ & $28.3 \pm 5.7$ & $26.9 \pm 4.7$ & $<0.001$ & $27.4 \pm 5.4$ & 0.04 \\
\hline ESS total & $7.8 \pm 4.7$ & $6.7 \pm 3.9$ & $<0.001$ & $6.4 \pm 4.7$ & 0.25 \\
\hline $\mathrm{BMI}>30(\%)$ & 37.2 & 27.1 & $<0.001$ & 33.2 & 0.048 \\
\hline Married (\%) & 66.2 & 76.0 & $<0.001$ & 65.7 & 0.013 \\
\hline Current smokers (\%) & 42.3 & 32.3 & 0.002 & 34.8 & 0.536 \\
\hline Exercise $\geq 2 \times$ per week (\%) & 37.6 & 46.1 & 0.001 & 39.4 & 0.06 \\
\hline \multicolumn{6}{|l|}{ Reported lifetime morbidity } \\
\hline CVD (\%) & 5.0 & 3.9 & 0.31 & 6.1 & 0.12 \\
\hline Diabetes (\%) & 8.4 & 3.5 & $<0.001$ & 6.1 & 0.05 \\
\hline Hypertension (\%) & 32.6 & 21.8 & $<0.001$ & 23.8 & 0.48 \\
\hline Depression (\%) & 21.7 & 15.3 & 0.001 & 32.9 & $<0.001$ \\
\hline
\end{tabular}

Significance is marked as bold.

BMI, body mass index; CVD, cardiovascular disease; ESS, Epworth Sleepiness Scale.

The mean age $( \pm \mathrm{SD})$ of the cohort was $54.2 \pm 7.1$ years (range: $39-67$ years), mean BMI was $27.0 \pm 4.8 \mathrm{~kg}$ / $\mathrm{m}^{2}, 28.1 \%$ were obese (BMI $\left.\geq 30\right), 33.2 \%$ were current smokers, $22.7 \%$ reported hypertension and $4.0 \%$ reported diabetes.

The mean sleep duration was $6.9 \pm 1.0$ hours per night. Overall, the majority of subjects $(88.1 \%)$ were normal sleepers (reporting sleeping 6-9hours per night). Short sleepers $(<6$ hours per night) and long sleepers ( $\geq 9$ hours per night) were $387(7.6 \%)$ and $217(4.3 \%)$ of the sample, respectively. Compared with short sleepers, normal sleepers were younger, had a lower BMI, were less likely to smoke, report hypertension or diabetes and were more likely to be married and to report exercising regularly. Additionally, short sleepers had a higher prevalence of diabetes, hypertension and depression as compared with normal sleepers. Long sleepers were older, more likely to be females, had a higher BMI, were less likely to be married and had a higher prevalence of diabetes and depression as compared with normal sleepers (table 1).

The box plot in figure 1 shows the median number of hours slept per night and the range of reported sleep duration in the different centres in the study. Even though the median is the same between all centres ( 7 hours), there was a considerable variation in range and reported mean sleep duration between centres, ranging from 6.4 in Huelva, Spain, to 7.1 hours per night in Reykjavik, Iceland $(\mathrm{p}<0.0001)$ (see figure 1$)$.

There was also a considerable difference between centres in the prevalence of being a short sleeper (the lowest was 2\% in Aarhus, Denmark, and the highest was
20.7\% in Huelva, Spain) (figure 2). The prevalence of long sleepers varied from $1.7 \%$ in Bergen, Norway, to $9.8 \%$ in Oviedo, Spain.

\section{SLEEP LENGTH AND RESPIRATORY SYMPTOMS}

All respiratory symptoms were more common in short sleepers as compared with normal sleepers (table 2). The prevalence of reporting having a blocked nose was also higher among short sleepers as compared with normal sleepers. Furthermore, short sleepers had a higher reported prevalence of nGOR and COPD as compared with normal sleepers. The only significant difference between long sleepers and normal sleepers was a higher prevalence of reporting shortness of breath after strenuous activity in long sleepers (table 2).

In the adjusted model, short sleep was associated to all respiratory and nasal symptoms except ever asthma and nasal allergies when the adjustment was without BMI. When BMI was also adjusted for, all symptoms except asthma were still associated with short sleep. Only a few symptoms were associated with long sleep duration (table 3).

The pooled estimates of the meta analyses of the association between short sleep and the respiratory variables were very similar to those found in table 3 (data not shown). No significant heterogeneity between the centres was found with the exception of the association between short sleep and shortness of breath following activity $\left(\mathrm{p}_{\text {heterogneity }}=0.04\right)$, being woken by cough $\left(\mathrm{p}_{\text {heterog. }}\right.$ ${ }_{\text {neity }}=0.01$ ) and cough during day and night in the winter $\left(\mathrm{p}_{\text {heterogneity }}=0.03\right)$. 


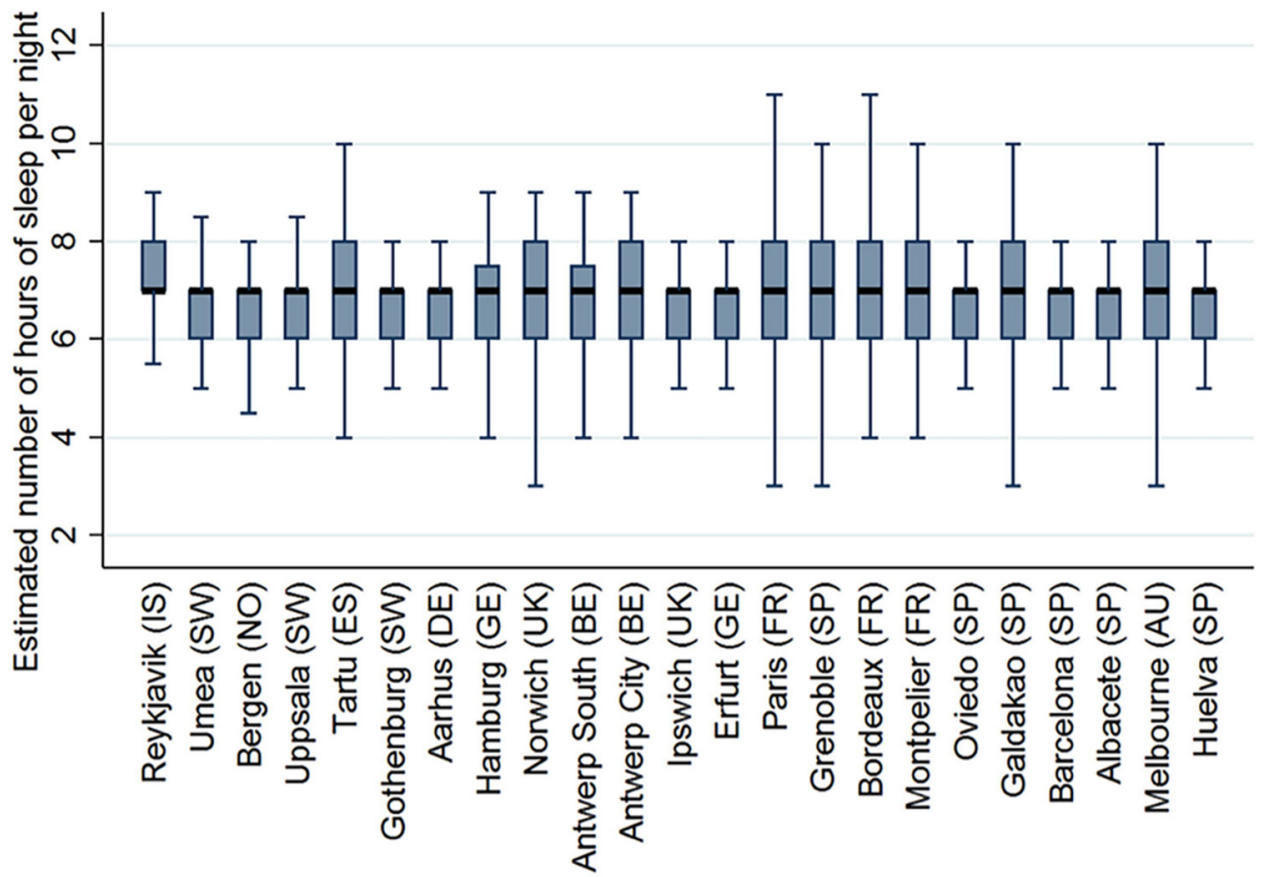

Figure 1 The median number of hours slept per night and the range in sleep length in different centres. Centres are sorted by latitude (from North to South).

Table 4 shows the adjusted associations of respiratory and nasal symptoms and sleep length for subjects with BMI $<30$ and $\mathrm{BMI} \geq 30$. Short sleep was related to 11 out of 16 nasal and respiratory symptoms among subjects with BMI $\geq 30$ and 9 out of 16 symptoms among subjects with BMI $<30$. Much fewer symptoms were related to long sleep, both for subjects with BMI $<30$ and $\geq 30$ (table 4).

\section{$\%$ of short sleepers}

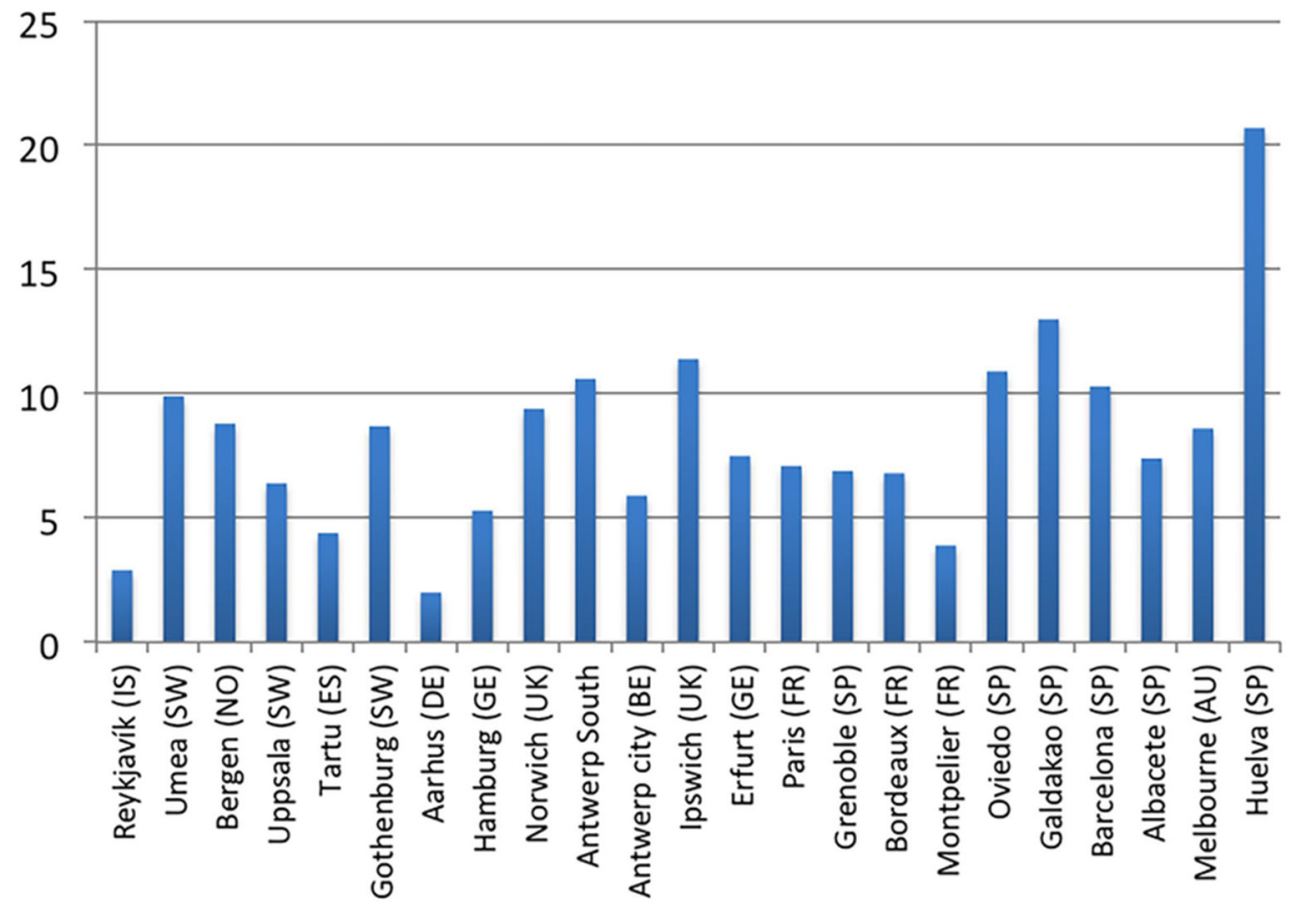

Figure 2 The prevalence (\%) of being a short sleeper in different centres. Centres are sorted by latitude (from North to South). 
Table 2 The prevalence (\%) of respiratory symptoms among short, normal and long sleepers

\begin{tabular}{|c|c|c|c|c|c|}
\hline & $\begin{array}{l}\text { Short } \\
\text { sleepers } \\
\text { (<6hours per } \\
\text { night) } n=462\end{array}$ & $\begin{array}{l}\text { Normal } \\
\text { sleepers } \\
\text { (6-9hours per } \\
\text { night) } n=5136\end{array}$ & $\begin{array}{l}\text { Short compared } \\
\text { with normal } \\
\text { sleepers } \\
\text { p Value }\end{array}$ & $\begin{array}{l}\text { Long } \\
\text { sleepers } \\
\text { ( } \geq 9 \text { hours per } \\
\text { night) } n=252\end{array}$ & $\begin{array}{l}\text { Long compared } \\
\text { with normal } \\
\text { sleepers } \\
\text { p Value }\end{array}$ \\
\hline Wheezing last 12 months & 35.7 & 23.2 & $<0.001$ & 25.4 & 0.951 \\
\hline $\begin{array}{l}\text { Woken with chest tightness last } \\
12 \text { months }\end{array}$ & 26.0 & 13.3 & $<0.001$ & 17.7 & 0.105 \\
\hline $\begin{array}{l}\text { Shortness of breath while at rest last } \\
12 \text { months }\end{array}$ & 14.0 & 6.8 & $<0.001$ & 7.9 & 0.291 \\
\hline $\begin{array}{l}\text { Shortness of breath after strenuous } \\
\text { activity last } 12 \text { months }\end{array}$ & 33.1 & 21.7 & $<0.001$ & 30.2 & 0.006 \\
\hline $\begin{array}{l}\text { Woken with shortness of breath last } \\
12 \text { months }\end{array}$ & 15.3 & 7.7 & $<0.001$ & 8.1 & 0.152 \\
\hline Woken by coughing last 12 months & 41.1 & 31.1 & 0.001 & 33.5 & 0.857 \\
\hline Cough in morning during the winter & 18.7 & 10.8 & $<0.001$ & 17.1 & 0.102 \\
\hline $\begin{array}{l}\text { Cough during day or night during the } \\
\text { winter }\end{array}$ & 27.4 & 15.1 & $<0.001$ & 19.1 & 0.928 \\
\hline Phlegm in morning during the winter & 20.7 & 12.7 & $<0.001$ & 16.0 & 0.635 \\
\hline $\begin{array}{l}\text { Phlegm during day or night during the } \\
\text { winter }\end{array}$ & 19.3 & 10.1 & $<0.001$ & 14.1 & 0.512 \\
\hline Chronic bronchitis & 10.8 & 6.2 & 0.011 & 9.6 & 0.420 \\
\hline nGOR & 20.0 & 14.0 & $<0.001$ & 14.5 & 0.984 \\
\hline Asthma ever & 17.5 & 18.9 & 0.474 & 23.1 & 0.224 \\
\hline COPD & 2.2 & 1.2 & 0.017 & 2.0 & 0.590 \\
\hline Nasal allergies including hay fever & 33.4 & 33.9 & 0.899 & 34.7 & 0.551 \\
\hline $\begin{array}{l}\text { Nose blocked for }>12 \text { weeks last } \\
12 \text { months }\end{array}$ & 14.3 & 7.1 & $<0.001$ & 10.0 & 0.244 \\
\hline
\end{tabular}

Significance $(p<0.05)$ is marked as bold. $p$ Values show comparisons of short sleepers versus normal sleepers and long sleepers versus normal sleepers.

COPD, chronic obstructive pulmonary disease; nGOR, nocturnal gastro-oesophageal reflux.

\section{DISCUSSION}

Our results show that short sleep duration is associated with many common respiratory symptoms and that this relationship is independent of obesity.

Given the known relationship between sleep duration and obesity, ${ }^{15}$ and obesity and respiratory symptoms, ${ }^{19} 20$ our hypothesis was that obesity was an important mediator to a possible association between sleep duration and respiratory symptoms. Interestingly, we found a significant relationship between short sleep duration and respiratory symptoms independent of obesity.

Previous studies have shown a strong relationship between sleep duration and obesity, ${ }^{15}$ hypertension ${ }^{10}$ and CVD. ${ }^{9}$ A recent study by Patel $e t a t^{4}$ found that short sleep was significantly associated with obesity with an OR of 1.29 (95\% CI 1.12 to 1.49 ) and a recent meta-analysis $^{11}$ showed a U-shaped dose-response relationship between extremes of sleep duration and metabolic syndrome. Metabolic syndrome has also been shown to be an independent risk factor for worsening of respiratory symptoms, lung function impairment and asthma. ${ }^{25}$ In our analysis, we made adjustments with and without
BMI in order to better understand the role of BMI in the associations of sleep length and respiratory symptoms. We also divided our sample into two groups, a group with $\mathrm{BMI}<30$ and $\mathrm{BMI} \geq 30$. We found in both groups a significant relationship between short sleep and respiratory symptoms. The high prevalence of respiratory symptoms associated with short sleep is therefore unlikely to be driven by the known associations of short sleep and obesity.

Our hypothesis was that obesity was a mediator in the relationship between sleep duration and respiratory symptoms. However, our results indicate a direct relationship not mediated by BMI. It is possible that respiratory symptoms are directly disrupting sleep (people waking up because of coughing, blocked nose, and so on). Others have reported associations between sleep disturbances and respiratory disorders. Klink and Quan ${ }^{26}$ found that individuals with asthma and bronchitis reported a high prevalence of difficulties initiating and maintaining sleep as well as daytime sleepiness. Leng $e t a l^{27}$ recently reported an association of excessive daytime napping with increased respiratory symptoms. In another general 
Table 3 Adjusted associations of respiratory symptoms and being short sleeper and long sleeper. Adjustment with $\dagger$ and without* BMI

\begin{tabular}{|c|c|c|c|c|}
\hline & $\begin{array}{l}\text { Short sleepers } \\
\text { Adj. OR }(95 \% \mathrm{Cl}) \\
\text { without } \mathrm{BMI}{ }^{*}\end{array}$ & $\begin{array}{l}\text { Short sleepers } \\
\text { Adj. OR ( } 95 \% \text { Cl) } \\
\text { with BMI † }\end{array}$ & $\begin{array}{l}\text { Long sleepers } \\
\text { Adj. OR }(95 \% \mathrm{Cl}) \\
\text { without BMI* }\end{array}$ & $\begin{array}{l}\text { Long sleepers } \\
\text { Adj. OR }(95 \% \mathrm{Cl}) \\
\text { with BMI }\end{array}$ \\
\hline Wheezing last 12 months & $1.76(1.29-2.39)$ & $1.54(1.12-2.13)$ & $0.94(0.60-1.45)$ & $0.94(0.59-1.50)$ \\
\hline Woken with chest tightness last 12 months & $2.37(1.67-3.36)$ & $2.10(1.45-3.03)$ & $1.24(0.75-2.04)$ & $0.98(0.55-1.76)$ \\
\hline $\begin{array}{l}\text { Shortness of breath while at rest last } \\
12 \text { months }\end{array}$ & $2.47(1.54-3.95)$ & $2.42(1.49-3.93)$ & $1.30(0.64-2.66)$ & $0.97(0.41-2.29)$ \\
\hline $\begin{array}{l}\text { Shortness of breath after strenuous activity } \\
\text { last } 12 \text { months }\end{array}$ & $1.81(1.32-2.49)$ & $1.55(1.10-2.19)$ & $1.75(1.19-2.58)$ & $1.80(1.17-2.77)$ \\
\hline $\begin{array}{l}\text { Woken with shortness of breath last } \\
12 \text { months }\end{array}$ & $2.48(1.62-3.81)$ & $2.40(1.55-3.72)$ & $1.94(1.07-3.51)$ & $1.66(0.85-3.22)$ \\
\hline Woken by coughing last 12 months & $1.54(1.15-2.07)$ & $1.43(1.05-1.94)$ & $1.12(0.76-1.63)$ & $1.10(0.73-1.66)$ \\
\hline Cough in morning during the winter & $1.96(1.37-2.83)$ & $2.01(1.38-2.92)$ & $1.51(0.92-2.47)$ & $1.68(1.00-2.80)$ \\
\hline Cough during day or night during the winter & $1.91(1.37-2.66)$ & $1.91(1.35-2.70)$ & $0.97(0.58-1.60)$ & $1.06(0.63-1.79)$ \\
\hline Phlegm in morning during the winter & $1.83(1.28-2.61)$ & $1.81(1.26-2.62)$ & $1.24(0.75-2.05)$ & $1.28(0.75-2.18)$ \\
\hline Phlegm during day or night during the winter & $2.00(1.38-2.90)$ & $2.02(1.38-2.96)$ & $1.17(0.67-2.05)$ & $1.04(0.56-1.93)$ \\
\hline Chronic bronchitis & $1.74(1.10-2.77)$ & $1.63(1.00-2.66)$ & $1.39(0.74-2.60)$ & $1.29(0.65-2.55)$ \\
\hline Asthma ever & $1.11(0.73-1.69)$ & $0.97(0.62-1.52)$ & $1.51(0.95-2.42)$ & $1.54(0.93-2.54)$ \\
\hline nGOR & $1.82(1.27-2.60)$ & $1.74(1.20-2.52)$ & $0.87(0.52-1.45)$ & $0.92(0.54-1.58)$ \\
\hline Chronic bronchitis & $1.74(1.10-2.77)$ & $1.63(1.00-2.66)$ & $1.39(0.75-2.60)$ & $1.23(0.65-2.54)$ \\
\hline COPD & $2.73(1.26-5.91)$ & $2.64(1.15-6.06)$ & $1.30(0.39-4.39)$ & $1.98(0.23-4.25)$ \\
\hline Nasal allergies including hay fever & $1.18(0.86-1.62)$ & $2.64(1.15-6.06)$ & $1.09(0.74-1.61)$ & $0.98(0.23-4.25)$ \\
\hline Nose blocked for $>12$ weeks last 12 months & $2.66(1.72-4.10)$ & $2.66(1.71-4.14)$ & $2.07(1.17-3.69)$ & $1.74(0.90-3.37)$ \\
\hline
\end{tabular}

Significance $(p<0.05)$ is marked as bold. Logistic regression model. Normal sleep length was used as a reference group.

${ }^{*}$ Adjusted for gender, age, centre, marital status, exercise and current smoking.

†Adjusted for gender, age, centre, marital status, exercise and current smoking and BMI.

$\mathrm{BMI}$, body mass index; COPD, chronic obstructive pulmonary disease; nGOR, nocturnal gastro-oesophageal reflux.

population study, specific respiratory symptoms such as coughing and wheezing were more predictive of sleep complaints than lung function or diagnosis of a lung disease. ${ }^{28}$ Furthermore, patients with COPD often experience sleep problems that lead to impaired quality of life. ${ }^{29}$ We have previously reported an association between asthma and reduced sleep quality and increased daytime sleepiness, ${ }^{30}{ }^{31}$ and an association between asthma and short sleep duration was recently reported in a large sample of Korean females, aged 19-29 years. ${ }^{32}$ Others have reported similar associations in children. ${ }^{33}$ Furthermore, several studies have reported associations between respiratory symptoms and insomnia. ${ }^{34}{ }^{35}$ It is however important to note that short sleepers in our study were more likely to smoke and even though we adjusted for this in our analysis this could account for some of the increase in respiratory symptoms in this group.

A relationship between untreated OSA and difficulties maintaining sleep has also been shown, ${ }^{36}$ where nighttime awakenings improve if OSA is treated, ${ }^{37}$ which supports the theory of respiratory disorders disrupting sleep. Short sleep could therefore be a marker of OSA, which is known to be associated to nGOR and other respiratory symptoms. ${ }^{38}$ Other studies have shown an association between OSA and short sleep duration. ${ }^{39}$ The subjects in our study from the Icelandic centre did however all have an overnight sleep study where OSA was estimated ${ }^{40}$ and those who were diagnosed with OSA did not report shorter sleep than the other subjects.

Respiratory symptoms have so far not been the main focus in studies on causal pathways of short sleep duration, but given our results some respiratory symptoms might directly impact sleep quality and increase the risk of short sleep duration. Our results indicate that sleep length needs to be one of the variables studied when exploring respiratory symptoms, and it may also be important for clinician working with respiratory patients to ask about their sleep habits.

In the present study, we also found that being a long sleeper was associated with a few respiratory symptoms and disorders. Others have reported associations between having asthma and being a long sleeper, ${ }^{41}$ which we replicated in this study among subjects with BMI $\geq 30$ only. Many previous studies have also shown a strong association between long sleep, depression and increased mortality. ${ }^{41}{ }^{42}$ The reason for the association between these respiratory symptoms and long sleep is not clear. It is possible that those with a history of respiratory 
Table 4 The adjusted ${ }^{\star}$ associations of respiratory disorders and sleep length for subjects with BMI $<30$ and subjects with $\mathrm{BMI} \geq 30$

\begin{tabular}{|c|c|c|c|c|}
\hline & $\begin{array}{l}\text { Short sleepers } \\
\mathrm{n}=387\end{array}$ & & $\begin{array}{l}\text { Long sleepers } \\
\mathrm{n}=217\end{array}$ & \\
\hline & $\begin{array}{l}\text { BMI }<30 \\
\mathrm{n}=243\end{array}$ & $\begin{array}{l}\text { BMI } \geq 30 \\
n=144\end{array}$ & $\begin{array}{l}\text { BMI }<30 \\
n=145\end{array}$ & $\begin{array}{l}\mathrm{BMI} \geq 30 \\
\mathrm{n}=72\end{array}$ \\
\hline Wheezing last 12 months & $1.37(0.92-2.04)$ & $2.55(1.53-4.26)$ & $0.89(0.51-1.56)$ & $1.00(0.48-2.12)$ \\
\hline Woken with tight chest last 12 months & $2.16(1.39-3.37)$ & $3.22(1.75-5.94)$ & $1.02(0.53-1.98)$ & $1.59(0.70-3.62)$ \\
\hline $\begin{array}{l}\text { Shortness of breath while in rest last } \\
12 \text { months }\end{array}$ & $3.13(1.74-5.63)$ & $1.37(0.59-3.19)$ & $1.08(0.38-3.07)$ & $1.58(0.55-4.50)$ \\
\hline $\begin{array}{l}\text { Shortness of breath after activity last } \\
12 \text { months }\end{array}$ & $1.47(0.96-2.26)$ & $2.33(1.38-3.93)$ & $1.94(1.19-3.18)$ & $1.48(0.75-2.91)$ \\
\hline Woken by shortness of breath last 12 months & $2.51(1.45-4.35)$ & $2.48(1.21-5.07)$ & $2.86(1.43-5.72)$ & $0.87(0.25-3.03)$ \\
\hline Woken by coughing last 12 months & $1.24(0.85-1.81)$ & $2.32(1.40-3.85)$ & $1.07(0.67-1.72)$ & $1.29(0.66-2.54)$ \\
\hline Cough in morning during the winter & $1.71(1.06-2.74)$ & $2.45(1.34-4.50)$ & $1.30(0.68-2.47)$ & $2.38(1.06-5.38)$ \\
\hline $\begin{array}{l}\text { Phlegm during day and night during the } \\
\text { winter }\end{array}$ & $1.91(1.19-3.06)$ & $2.17(1.15-4.09)$ & $0.84(0.39-1.83)$ & 1.85 (0.78-4.39) \\
\hline Asthma ever & $1.02(0.60-1.75)$ & $1.27(0.62-2.61)$ & $1.09(0.58-2.07)$ & $2.78(1.31-5.90)$ \\
\hline nGOR & $2.16(1.36-3.41)$ & $1.37(0.75-2.49)$ & $1.26(0.70-2.27)$ & $0.40(0.13-1.18)$ \\
\hline Chronic bronchitis & $1.50(0.77-2.88)$ & $1.95(0.97-3.95)$ & $1.45(0.67-3.12)$ & $1.29(0.42-3.94)$ \\
\hline COPD & $1.50(0.78-2.88)$ & $5.67(1.62-19.8)$ & $1.45(0.67-3.13)$ & $2.41(0.46-12.7)$ \\
\hline Nasal allergies including hay fever & $1.16(0.77-1.73)$ & $1.26(0.73-2.17)$ & $1.19(0.74-1.90)$ & $0.94(0.46-1.95)$ \\
\hline $\begin{array}{l}\text { Nose blocked for more than } 12 \text { weeks for the } \\
\text { last } 12 \text { months }\end{array}$ & 2.59 (1.49-4.49) & $2.77(1.31-5.84)$ & $1.40(0.62-3.15)$ & $4.10(1.67-10.08)$ \\
\hline
\end{tabular}

${ }^{*}$ Adjusted for gender, age, centre, marital status, exercise and current smoking. Significance $(p<0.05)$ is marked as bold. Logistic regression model. Normal sleep length was used as a reference group.

BMI, body mass index; COPD, chronic obstructive pulmonary disease; nGOR, nocturnal gastro-oesophageal reflux.

symptoms are more unwell and less active, which could facilitate longer sleep. ${ }^{41}$ Also, increased inflammation and elevated cytokines among subjects with respiratory symptoms could lead to increased fatigue and hence produce longer sleep. ${ }^{43-45}$ Our results show that short sleep is much more strongly related to respiratory symptoms than long sleep, but these associations need to be studied further.

There were considerable differences in sleep duration in different centres in our study and the highest percentage of short sleepers were in the Spanish centres. Cultural differences, such as siestas or afternoon napping, may impact sleep duration.

There are several limitation of this study that need to be considered. Our results are from a cross-sectional study, and deeper understanding of the underlying causal pathways can only come from prospective or intervention studies. Information regarding sleep duration was self-reported without any objective measure on sleep time. However, sleep length, as reported in questionnaires, correlates well with sleep diaries. ${ }^{7}$ Also, most symptoms were reported as present for the past 12 months, and therefore it is not clear if these symptoms were currently present when the study took place. Furthermore, we did not have information on daytime napping, which could affect nighttime sleep length. The strengths of this study include the population-based nature of this large sample from many centres in 10 different countries and the use of standardised and validated procedures and instruments.

To summarise, our results show that reporting respiratory symptoms is related to sleep duration, especially with reported short sleep. Short sleepers report more respiratory symptoms, and this association is not confined to those who are obese. To our knowledge, this is the first report of an association between respiratory symptoms and sleep length in a large population-based cohort of middle-aged subjects. There is a need for prospective studies on sleep length and respiratory symptoms in order to clarify how short and/or long sleep are associated to respiratory health.

\section{Author affiliations}

${ }^{1}$ Department of Respiratory Medicine and Sleep, Landspitali - The National University Hospital of Iceland, Reykjavik, Iceland

${ }^{2}$ Faculty of Medicine, University of Iceland, Reykjavík, Iceland 
${ }^{3}$ Department of Medical Sciences: Respiratory, Allergy and Sleep Research, Uppsala University, Uppsala, Sweden

${ }^{4}$ Faculty of Medicine, University of Iceland, Reykjavik, Iceland

${ }^{5}$ ISGlobal, Centre for Research in Environmental Epidemiology (CREAL),

Barcelona, Spain

${ }^{6}$ Universitat Pompeu Fabra (UPF), Barcelona, Spain

${ }^{7}$ CIBER Epidemiología y Salud Pública (CIBERESP), Barcelona, Spain

${ }^{8}$ Department of Clinical Science, University of Bergen, Bergen, Norway

${ }^{9}$ Department of Occupational and Environmental Medicine, Institute of

Medicine, Sahlgrenska Academy, University of Gothenburg, Gothenburg,

Sweden

${ }^{10}$ Ludwig Maximilians University Munich, Ludwig Maximilians University

Munich, University Hospital Munich, Institute and Outpatient Clinic for

Occupational, Social and Environmental Medicine, Munich, Germany

${ }^{11}$ Helmholtz Zentrum München, German Research Center for Environmental

Health, Institute of Epidemiology I, Neuherberg, Germany

${ }^{12}$ Department of Nursing, University of Huelva, Huelva, Spain

${ }^{13}$ Department of Pneumology, University Hospital of Montpellier, Montpellier, France

${ }^{14}$ Pulmonology Department, Galdakao-Usansolo Hospital, Biscay, Spain

${ }^{15}$ Unidad del Sueño, Servicio de Neumología, Hospital General Universitario, Albacete, Spain

${ }^{16}$ Department of Public Health, Aarhus University, Aarhus, Denmark

${ }^{17}$ National Research Centre for the Working Environment, Copenhagen, Denmark

${ }^{18}$ U1219, Bordeaux Population Health Research Center, Bordeaux, France

${ }^{19}$ Population Health and Occupational Disease, National Heart and Lung

Institute, Imperial College London, London, UK

${ }^{20}$ MRC-PHE Centre for Environment and Health, Imperial College London, London, UK

Contributors EB drafted the paper, participated in designing the study and performed the statistical analysis. $\mathrm{CJ}$ and EL designed the study, participated in manuscript preparation and reviewed the paper on several stages. CJ also contributed to the statistical analysis. BB participated in data collection and reviewing the paper. ESA contributed to the statistical analysis and reviewed the paper, JG-A, AEC, FGR, KT, JH, DN, JLS, PD, SDA, RCN, VS, CR and DLJ. TG is the correspondence author, and he designed the study, participated in manuscript preparation and reviewed the paper on several stages.

Funding The ALEC Study is funded by the European Union's Horizon 2020 Research and Innovation programme under grant agreement № 633212.

Competing interests None declared.

Patient consent Detail has been removed from this case description/these case descriptions to ensure anonymity. The editors and reviewers have seen the detailed information available and are satisfied that the information backs up the case the authors are making.

Ethics approval Ethical approval for the study from local research ethics committees and written consent from participants were obtained.

Provenance and peer review Not commissioned; externally peer reviewed.

Data sharing statement № additional data available.

Open Access This is an Open Access article distributed in accordance with the Creative Commons Attribution Non Commercial (CC BY-NC 4.0) license, which permits others to distribute, remix, adapt, build upon this work non-commercially, and license their derivative works on different terms, provided the original work is properly cited and the use is non-commercial. See: http://creativecommons.org/ licenses/by-nc/4.0/

C) Article author(s) (or their employer(s) unless otherwise stated in the text of the article) 2017. All rights reserved. No commercial use is permitted unless otherwise expressly granted.

\section{REFERENCES}

1. James PT, Leach R, Kalamara E, et al. The worldwide obesity epidemic. Obes Res 2001;9 Suppl 4:228S-33.

2. Van Cauter E, Knutson KL. Sleep and the epidemic of obesity in children and adults. Eur J Endocrinol 2008;159 Suppl 1:S59-S66.

3. National Sleep Foundation. Sleep in America Poll. Washington, DC: National Sleep Foundation, 2008.
4. National Center for Health StatisticsQuickStats: percentage of adults who reported an average of $\leq 6$ hours of sleep per 24-hour period by sex and age group - United States, 1985 and 2004. MMWR Morb Mortal Wkly Re 2005;54:933.

5. Kripke DF, Simons RN, Garfinkel L, et al. Short and long sleep and sleeping pills. is increased mortality associated? Arch Gen Psychiatry 1979;36:103-16.

6. Kripke DF, Garfinkel L, Wingard DL, et al. Mortality associated with sleep duration and insomnia. Arch Gen Psychiatry 2002;59:131-6.

7. Patel SR, Ayas NT, Malhotra MR, et al. A prospective study of sleep duration and mortality risk in women. Sleep 2004;27:440-4.

8. Al Lawati NM, Patel SR, Ayas NT. Epidemiology, risk factors, and consequences of obstructive sleep apnea and short sleep duration. Prog Cardiovasc Dis 2009;51:285-93.

9. Badran M, Yassin BA, Fox N, et al. Epidemiology of Sleep Disturbances and Cardiovascular Consequences. Can J Cardiol 2015;31:873-9.

10. Gottlieb DJ, Redline S, Nieto FJ, et al. Association of usual sleep duration with hypertension: the Sleep Heart Health Study. Sleep 2006;29:1009-14.

11. Donley M, Mindel J, Pleister A, et al. Sleep Duration and metabolic syndrome: a Dose-Risk Meta-Analysis. Am J Respir Crit Care Med 2015;191:A2152.

12. Buscemi D, Kumar A, Nugent R, et al. Short sleep times predict obesity in internal medicine clinic patients. J Clin Sleep Med 2007;3:681-8.

13. Stranges S, Dorn JM, Shipley MJ, et al. Correlates of short and long sleep duration: a cross-cultural comparison between the United Kingdom and the United States: the Whitehall II Study and the western New York Health Study. Am J Epidemiol 2008;168:1353-64.

14. Theorell-Haglöw J, Berglund L, Janson C, et al. Sleep duration and central obesity in women - differences between short sleepers and long sleepers. Sleep Med 2012;13:1079-85.

15. Zhang S, Li L, Huang Y, et al. [Meta-analysis of prospective cohort studies about sleep duration and risk of weight gain and obesity in adults]. Zhonghua Liu Xing Bing Xue Za Zhi 2015;36:519-25.

16. Schaub B, von Mutius E. Obesity and asthma, what are the links? Curr Opin Allergy Clin Immunol 2005;5:185-93.

17. Guerra S, Sherrill DL, Bobadilla A, et al. The relation of body mass index to asthma, chronic bronchitis, and emphysema. Chest 2002;122:1256-63.

18. Young T, Skatrud J, Peppard PE. Risk factors for obstructive sleep apnea in adults. JAMA 2004;291:2013-6.

19. Murugan AT, Sharma G. Obesity and respiratory diseases. Chron Respir Dis 2008;5:233-42.

20. Mebrahtu TF, Feltbower RG, Greenwood DC, et al. Childhood body mass index and wheezing disorders: a systematic review and metaanalysis. Pediatr Allergy Immunol 2015;26:62-72.

21. Burney PG, Luczynska C, Chinn S, et al. The European Community Respiratory Health Survey. Eur Respir J 1994;7:954-60.

22. Janson C, Anto J, Burney P, et al. European Community Respiratory Health Survey II. The European Community Respiratory Health survey: what are the main results so far? European Community Respiratory Health Survey II. Eur Respir J 2001;18:598-611.

23. Johns MW. Reliability and factor analysis of the Epworth Sleepiness Scale. Sleep 1992;15:376-81.

24. Patel SR, Sotres-Alvarez D, Castañeda SF, et al. Social and Health Correlates of Sleep Duration in a US Hispanic Population: results from the Hispanic Community Health Study/Study of Latinos. Sleep 2015;38:1515-22.

25. Baffi CW, Wood L, Winnica D, et al. Metabolic syndrome and the lung. Chest 2016;149:1525-34.

26. Klink M, Quan SF. Prevalence of reported sleep disturbances in a general adult population and their relationship to obstructive airways diseases. Chest 1987:91:540-6.

27. Leng Y, Wainwright NW, Cappuccio FP, et al. Daytime napping and increased risk of incident respiratory diseases: symptom, marker, or risk factor? Sleep Med 2016;23:12-15.

28. Klink ME, Dodge R, Quan SF. The relation of sleep complaints to respiratory symptoms in a general population. Chest 1994:105:151-4.

29. Scharf SM, Maimon N, Simon-Tuval T, et al. Sleep quality predicts quality of life in chronic obstructive pulmonary disease. Int $J$ Chron Obstruct Pulmon Dis 2010;6:1-12.

30. Janson C, De Backer W, Gislason T, et al. Increased prevalence of sleep disturbances and daytime sleepiness in subjects with bronchial asthma: a population study of young adults in three european countries. Eur Respir J 1996;9:2132-8.

31. Janson C, Gislason T, Boman G, et al. Sleep disturbances in patients with asthma. Respir Med 1990;84:37-42 
32. Choi JH, Nam GE, Kim DH, et al. Association between sleep duration and the prevalence of atopic dermatitis and asthma in young adults. Asian Pac J Allergy Immunol 2016.

33. Jensen ME, Gibson PG, Collins CE, et al. Increased sleep latency and reduced sleep duration in children with asthma. Sleep Breath 2013:17:281-7.

34. Dodge R, Cline MG, Quan SF. The natural history of insomnia and its relationship to respiratory symptoms. Arch Intern Med 1995;155:1797-800.

35. Taylor DJ, Mallory LJ, Lichstein KL, et al. Comorbidity of chronic insomnia with medical problems. Sleep 2007;30:213-8.

36. Björnsdóttir E, Janson C, Gíslason T, et al. Insomnia in untreated sleep apnea patients compared to controls. J Sleep Res 2012;21:131-8.

37. Bjornsdottir E, Janson C, Arnard?ttir E, et al. Symptoms of insomnia among OSA patients before and after 2years of PAP treatment. Sleep Med 2013;14:e74.

38. Emilsson OI, Janson C, Benediktsdóttir B, et al. Nocturnal gastroesophageal reflux, lung function and symptoms of obstructive sleep apnea: results from an epidemiological survey. Respir Med 2012;106:459-66.

39. Chin K, Oga T, Takahashi K, et al. Associations between obstructive sleep apnea, metabolic syndrome, and sleep duration, as measured with an actigraph, in an urban male working population in Japan. Sleep 2010;33:89-95.

40. Arnardottir ES, Bjornsdottir E, Olafsdottir KA, et al. Obstructive sleep apnoea in the general population: highly prevalent but minimal symptoms. Eur Respir J 2016;47:194-202.

41. Patel SR, Malhotra A, Gottlieb DJ, et al. Correlates of long sleep duration. Sleep 2006;29:881-9.

42. Sivertsen B, Øverland S, Pallesen S, et al. Insomnia and long sleep duration are risk factors for later work disability. The Hordaland Health Study. J Sleep Res 2009;18:122-8.

43. Vgontzas AN, Papanicolaou DA, Bixler EO, et al. Elevation of plasma cytokines in disorders of excessive daytime sleepiness: role of sleep disturbance and obesity. J Clin Endocrinol Metab 1997;82:1313-6.

44. Williams CJ, Hu FB, Patel SR, et al. Sleep duration and snoring in relation to biomarkers of cardiovascular disease risk among women with type 2 diabetes. Diabetes Care 2007:30:1233-40.

45. Irwin MR, Olmstead R, Carroll JE. Sleep disturbance, Sleep Duration, and inflammation: a systematic review and Meta-Analysis of Cohort Studies and experimental Sleep Deprivation. Biol Psychiatry 2016;80:40-52. 